\title{
Spinal glucocorticoid receptor-regulated chronic morphine tolerance may be through extracellular signal-regulated kinase 1/2
}

\author{
MEI-LI ZHAI ${ }^{1 *}$, YI CHEN $^{2 *}$, CHONG LIU $^{3}$, JIAN-BO WANG $^{1}$ and YONG-HAO YU ${ }^{2}$ \\ ${ }^{1}$ Department of Anesthesiology, Tianjin Center Obstetrics and Gynecology Hospital, \\ Central Obstetrics and Gynecology Hospital of Nankai University, Tianjin 300100; ${ }^{2}$ Department of Anesthesiology, \\ General Hospital of Tianjin Medical University, Tianjin 300052; ${ }^{3}$ Department of Anesthesiology, Tianjin Fourth Central Hospital, \\ The Fourth Central Hospital Affiliated to Nankai University, Tianjin 300140, P.R. China
}

Received October 28, 2017; Accepted April 17, 2018

DOI: $10.3892 / \mathrm{mmr} .2018 .9057$

\begin{abstract}
Opioid use has been limited in the treatment of chronic pain due to their side effects, including analgesic tolerance. Previous studies demonstrated that glucocorticoid receptors (GRs) may be involved in the development of chronic morphine tolerance; however, the mechanism remains unknown. It was hypothesized that the expression of spinal phosphorylated mitogen-activated protein kinase [MAPK; phosphorylated extracellular signal-regulated kinase (ERK)] is regulated through the spinal GRs, following chronic treatment with morphine. In the first experiment, the experimental rats were randomly divided into four groups: Control, morphine, morphine+GR antagonist mifepristone (RU38486) and morphine+GR agonist dexamethasone (Dex). Each group was treated with continuous intrathecal (IT) injection of the drugs for 6 days. The expression of GRs and MAPK 3/1 (p-ERK 1/2) in the spinal dorsal horn was detected by western blot analysis and immunofluorescence staining. In the second experiment, the MAPK inhibitor PD98059 was added and the rats were randomly divided into four groups: Control, morphine, PD98059+morphine and PD98059+morphine+Dex. The continuous IT injection lasted for 7 days in each group. For all experiments, the tail flick test was conducted 30 min following administration every day to assess the thermal hyperalgesia of the rats. The experimental results demonstrated that there was a co-existence of GRs and p-ERK 1/2 in the spinal cord dorsal horn by double immunofluorescence staining. The GR antagonist RU38486 attenuated the morphine analgesia tolerance by
\end{abstract}

Correspondence to: Dr Yong-Hao Yu, Department of Anesthesiology, General Hospital of Tianjin Medical University, 154 Anshan Road, Heping, Tianjin 300052, P.R. China

E-mail:rsb862@163.com

*Contributed equally

Key words: chronic morphine tolerance, glucocorticoid receptor, mifepristone, extracellular signal-regulated kinase inhibiting the expression of GR and increasing the expression of p-ERK. The MAPK inhibitor PD98059 increased the effect of morphine tolerance and prolonged the duration of morphine tolerance. The present results suggest that spinal GRs may serve an important role in the development of morphine tolerance through the ERK signaling pathway.

\section{Introduction}

Opioids are used clinically for pain management; they exert an anti-nociceptive effect by activating $\mu$-opioid receptors located in the dorsal root ganglia, spinal cord and brain. However, their continuous administration, particularly morphine, is associated with the development of analgesic tolerance. Investigation into the mechanisms of morphine tolerance has been a focus of interest for numerous years (1-5). Certain studies have suggested that the spinal glucocorticoid receptors (GRs) may serve an important role in the mechanisms of morphine tolerance $(6,7)$; however, the molecular and cellular mechanisms underlying morphine tolerance remain undetermined.

During the past two decades, a number of associated intracellular signaling cascades, including the mitogen-activated protein kinase (MAPK) signaling cascades have been described. MAPKs may be activated by morphine via opioid receptors, and their activation has been observed in synaptic plasticity and addiction (8-14). In vivo, a role of MAPKs in opioid analgesia and sedation has additionally been proposed (15). The extracellular signal-regulated kinase (ERK) pathway is among numerous signal transduction pathways that may alter gene expression in distinct brain regions in response to repeated opioid exposure $(15,16)$.

Neuronal GRs have been located within a number of central regions and implicated in neuronal plastic alterations $(17,18)$. The regulatory role of GR may be critical to the cellular mechanisms of morphine tolerance, as the development of morphine tolerance was attenuated by the GR antagonist RU38486 (6,7). Furthermore, the GR-mediated effect on morphine tolerance was abolished in adrenalectomized rats, indicating that endogenous corticosteroids serve an important role in GR function following chronic morphine exposure (19). Clark and Lasa (20) summarized the association between glucocorticoids and the MAPK signaling pathways. 
The GR and ERK pathways are involved in neuropathic pain, which shares the same mechanism as morphine tolerance (21-23). In a rat model of morphine tolerance, the hypothesis that spinal GRs may serve an important role in the development of tolerance to the antinociceptive effect of morphine through ERK was examined in the present study.

\section{Materials and methods}

Animals. A total of 50 male Sprague-Dawley rats (10-12 weeks old, weighing 250-350 g) were used in the present study. The animals were provided by the Peking Union Medical College Animal Center (Beijing, China) and were housed in plastic cages, with free access to water and food available ad libitum. The rats were housed under 12-h light/dark conditions in a room with controlled temperature $\left(22-26^{\circ} \mathrm{C}\right)$ and relative humidity (60-80\%). The animals adapted to this environment for 7 days prior to the start of the experiment, and every effort was made to minimize the number of animals used and their suffering. All animal procedures in the present study were approved by the Animal Care and Use Committee of Tianjin Medical University and in accordance with the National Institutes of Health Guide for the Care and Use of Laboratory Animals.

Implantation of intrathecal (IT) catheters and administration of drugs. Under anesthesia with chloral hydrate $[300 \mathrm{mg} / \mathrm{kg}$ by intraperitoneal (IP) injection], a PE10 catheter was implanted in each rat, according to a previously published method (24), inserting to the level of the lumbar enlargement $(7.5 \mathrm{~cm}$ from the incision site). A total of five animals that exhibited neurological defects, including paralysis, following the IT catheter implantation were excluded from the experiments (25). The rats were housed individually following surgery and recovered for 3 days prior to the following test. An IT treatment regimen of $10 \mu \mathrm{g}$ morphine was given twice daily for 6 consecutive days to induce chronic morphine tolerance. The following drugs were purchased from Sigma-Aldrich; Merck KGaA (Darmstadt, Germany): Mifepristone (RU38486; batch no. M8046); dexamethasone (Dex; batch no. D1756); and PD98059 (batch no. P215). Morphine was dissolved in normal saline and PD98059 was dissolved in a $0.4 \%$ dimethyl sulfoxide solution. The other drugs were dissolved in a $10 \%$ ethanol solution (Table I).

Behavioral tests. The tail flick latency (TFL) was used as an index to evaluate antinociceptive responses to thermal pain. During the TFL testing, a rat was placed in a hard plastic fixator, and the rat tail was immersed in hot water $\left(52 \pm 0.5^{\circ} \mathrm{C}\right)$ $3 \mathrm{~cm}$ from the distal end of the tail (26). The routine tail-flick test was used with baseline latencies of 3-4 sec and a cutoff time of $10 \mathrm{sec}$. The TFL was measured in each rat $30 \mathrm{~min}$ following injection every morning. Each measurement was repeated three times to reduce aberration, with a measurement interval of $1 \mathrm{~min}$. The baseline value was determined on the first day prior to the first injection. In order to make the animal accustomed and remain quiet in the tail flick test situation, $\sim$ one week prior to the start of the test, the rats were allowed to acclimate in the test environment for $2 \mathrm{~h}$ per day, and were intermittently confined to the tubular rat fixator to adapt to the pre-experimental state. During each test session, the animals were tested with 20 min intervals during $2 \mathrm{~h}$ and were free to exercise without any stimulation

Immunofluorescent staining. Under anesthesia with chloral hydrate $(300 \mathrm{mg} / \mathrm{kg}$ IP), the lumbar spinal cord segments 3-5 $\left(\mathrm{L}_{3-5}\right)$ were dissected, and subsequently mounted in optimum cutting temperature compound and frozen on dry ice. A total of five spinal cord sections $(5-\mu \mathrm{m})$ per animal were fixed with cold pure acetone $(0.7845 \mathrm{~g} / \mathrm{ml})$ for $20 \mathrm{~min}$ at $4{ }^{\circ} \mathrm{C}$, and incubated with $0.3 \% \mathrm{H}_{2} \mathrm{O}_{2}$ solution for $10 \mathrm{~min}$. The sections were blocked with $1 \%$ bovine serum (Tianjin Jiaguan Biotechnology Development Center, Tianjin, China; numbered shs j-4) in $0.3 \%$ Triton $\mathrm{X}-100$ for $30 \mathrm{~min}$ at $37^{\circ} \mathrm{C}$ and subsequently incubated overnight at $4^{\circ} \mathrm{C}$ with a primary antibody against GRs (1:50, rabbit polyclonal; Santa Cruz Biotechnology, Inc., Dallas, TX, USA) and phosphorylated (p)-ERK1/2 (1:300, rabbit monoclonal; cat. no. ab201015; Abcam, Cambridge, UK). The sections were incubated for $1 \mathrm{~h}$ at $37^{\circ} \mathrm{C}$ with a corresponding tetramethylrhodamine- or fluorescein isothiocyanate-conjugated secondary antibody (1:50; Santa Cruz Biotechnology, Inc.). For double staining, a second primary antibody was added following the incubation with the first primary antibody, following the same procedure as described above. A total of four to six nonadjacent spinal sections were randomly selected, analyzed using a fluorescence microscope (Olympus Corporation, Tokyo, Japan) at a magnification, x400 and processed using Adobe Photoshop CS3 10.0.1 (Adobe Systems, Inc., San Jose, CA, USA).

Western blot analysis. The rats were rapidly $(<1 \mathrm{~min})$ sacrificed by decapitation on day 7 , subsequent to being anesthetized with an IP injection of $300 \mathrm{mg} / \mathrm{kg}$ chloral hydrate. $\mathrm{L}_{3-5}$ were removed and immediately frozen in liquid nitrogen and stored at $-80^{\circ} \mathrm{C}$ until the protein extraction was conducted. Tissues were homogenized in $50 \mathrm{mM}$ radioimmunoprecipitation buffer (20 $\mu \mathrm{l} / \mathrm{mg}$ ) containing protease and phosphatase inhibitors. The homogenates were incubated on ice for $30 \mathrm{~min}$ and centrifuged at $12,000 \mathrm{x}$ g for $15 \mathrm{~min}$ at $4^{\circ} \mathrm{C}$ and the supernatant was removed and stored at $-20^{\circ} \mathrm{C}$. The protein was lysed by PRO-PREP Protein Extraction Solution (iNtRON Biotechnology, Sungnam, Korea), and total protein concentrations were determined spectrophotometrically using the bicinchoninic acid method. The protein samples were mixed with equal volumes of electrophoresis loading buffer, boiled for $15 \mathrm{~min}$ and centrifuged at $800 \mathrm{xg}$ at $12,000 \mathrm{x} \mathrm{g}$ for $10 \mathrm{~min}$, at $4^{\circ} \mathrm{C}$. The samples $(20 \mu \mathrm{g})$ were subsequently separated using $15 \%$ SDS-PAGE and transferred electrophoretically to a nitrocellulose membrane. The membranes were blocked in 5\% skim milk in TBST buffer [10 mM Tris (pH 7.5), $150 \mathrm{mM} \mathrm{NaCl,} \mathrm{0.1 \%} \mathrm{Tween-20]} \mathrm{for} 1 \mathrm{~h}$ at room temperature and incubated with primary antibody, including mouse monoclonal anti-GR (1:1,000; cat. no. ab9568; Abcam), rabbit monoclonal anti-phospho-ERK1/2 (1:10,000; cat. no. ab201015; Abcam), and mouse monoclonal anti-ERK1/2 (1:10,000; cat. no. ab54230; Abcam), and were gently agitated overnight at $4^{\circ} \mathrm{C}$. The blots were rinsed three times for $30 \mathrm{~min}$ in TBST and incubated for $2 \mathrm{~h}$ at room temperature with the appropriate anti-rabbit (cat. no. 7074) and anti-mouse (cat. no. 7076) secondary horseradish peroxidase-conjugated 
Table I. Experimental groups.

A, Experiment 1

\begin{tabular}{lcccccc}
\hline Group & Saline, $\mu \mathrm{l}$ & Morphine, $\mu \mathrm{g}$ & $\mathrm{RU} 38486, \mu \mathrm{g}$ & Dex, $\mu \mathrm{g}$ & $0.4 \%$ DMSO, $\mu \mathrm{l}$ & $\mathrm{PD} 98059, \mu \mathrm{g}$ \\
\hline $\mathrm{C}$ & 1 & - & - & - & - & - \\
M & - & 10 & - & - & - & - \\
M/D & - & 10 & 2 & - & - & - \\
M/R & - & 10 & & \\
\hline
\end{tabular}

B, Experiment 2

\begin{tabular}{|c|c|c|c|c|c|c|}
\hline Group & Saline, $\mu 1$ & Morphine, $\mu \mathrm{g}$ & RU38486, $\mu \mathrm{g}$ & $\operatorname{Dex}, \mu \mathrm{g}$ & $0.4 \%$ DMSO,$\mu 1$ & PD98059, $\mu \mathrm{g}$ \\
\hline $\mathrm{C}$ & 1 & - & - & - & 10 & - \\
\hline M & - & 10 & - & - & - & - \\
\hline $\mathrm{P}$ & - & 10 & - & - & - & 10 \\
\hline $\mathrm{P}+\mathrm{D}$ & - & 10 & - & 4 & - & 10 \\
\hline
\end{tabular}

C, control; M, morphine; M/D, morphine+Dex; M/R, morphine+RU38486; P, PD98059+morphine; Dex, dexamethasone; RU38486, mifepristone; DMSO, dimethyl sulfoxide.

antibodies (1:2,000; Cell Signaling Technology, Inc.). Reactive protein was detected using an enhanced chemiluminescence system (Amersham ECL ${ }^{\mathrm{TM}}$; GE Healthcare, Chicago, IL, USA). $\beta$-actin was the loading control for all the experiments. The ratio of GR/ $\beta$-actin, p-ERK/ $\beta$-actin and $p$-ERK/total ERK were plotted and analyzed by ImageJ Software (version 1.49; National Institutes of Health, Bethesda, MD, USA). All the western blot analyses were performed at least three times and consistent results were obtained.

Statistical analysis. All results presented are expressed as the mean \pm standard error of the mean as indicated. All experimental data were repeated three times. The significance of differences was calculated using repeated measure one-way analysis of variance followed with post-hoc Newman-Keuls tests. Statistical analysis was performed with SPSS 19.0 software (IBM Corp., Armonk, NY, USA). P<0.05 was considered to indicate a statistically significant difference.

\section{Results}

Development of morphine tolerance and the effect of RU38486. The baseline TFL $(3.25 \pm 0.52 \mathrm{sec} ; \mathrm{n}=20)$ was determined on the first day prior to injection of all the rats. The IT administration of morphine for 6 days led to the development of tolerance to morphine-induced analgesia (Fig. 1). As the figure demonstrates, the injection of morphine produced a significant analgesia to thermal stimuli on day 1 [\% maximal possible effect $(\mathrm{MPE})=87.82 \pm 10.40 \%$ ] compared with the control group; however, the effect of morphine gradually declined during the following days (between day 3 and day $7 ; \mathrm{P}<0.05$ ), demonstrating that the rats had developed morphine tolerance. However, cotreatment of the GR antagonist RU38486 with morphine for 6 consecutive days inhibited the morphine antinociceptive tolerance; the \%MPE was $54.07 \pm 11.32$ on day 7 , significantly higher

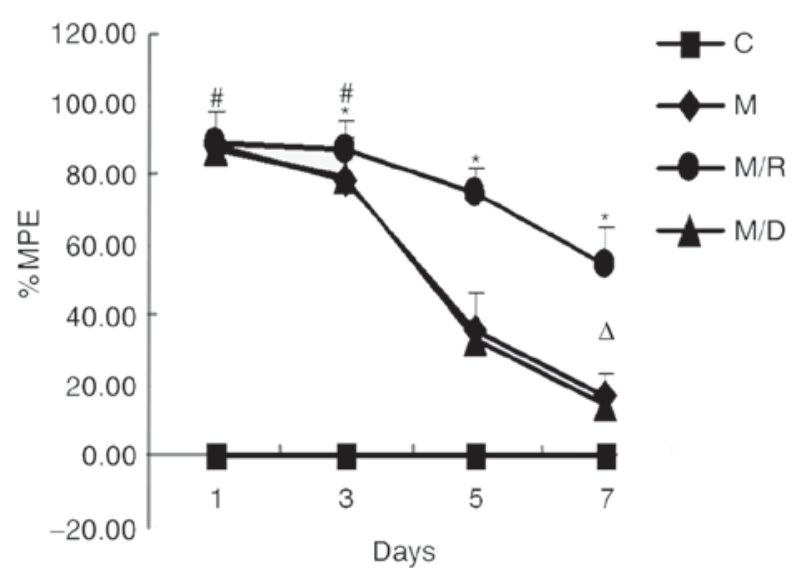

Figure 1. Effects of morphine combined with RU38486 or dexamethasone, or morphine alone in the tail-flick test. ${ }^{*} \mathrm{P}<0.05$ vs. $\mathrm{M} ;{ }^{\#} \mathrm{P}<0.05$ vs. $\mathrm{C} ;{ }^{\Delta} \mathrm{P}>0.05$ vs. M. $\mathrm{n}=5$ for each group. C, saline treatment for 6 days ( $10 \mu 1$, twice daily); $\mathrm{M}$, treatment with morphine for 6 days (10 $\mu \mathrm{g}$ twice daily); M/R, cotreatment of morphine $(10 \mu \mathrm{g})$ and RU38486 $(2 \mu \mathrm{g})$ for 6 days twice daily; M/D, cotreatment of morphine $(10 \mu \mathrm{g})$ and RU38486 $(4 \mu \mathrm{g})$ for 6 days twice daily; MPE, maximal possible effect; RU348486, mifepristone.

compared with the morphine group $(16.88 \pm 11.88 ; \mathrm{P}<0.05$; Fig. 1). These findings suggested that the GR antagonist may inhibit the development of morphine tolerance.

Effects of pretreatment with PD98059 in morphine-tolerant rats. Coadministration of morphine $(10 \mu \mathrm{g})$ and Dex $(4 \mu \mathrm{g})$ given twice daily for 7 days significantly accelerated the development of morphine tolerance (\%MPE $=14.93 \pm 8.29 \%$; Fig. 2). On day 5, the \%MPE was $20.40 \pm 17.07 \%$ in the morphine group; pretreatment with the MEK inhibitor PD98059 prior to $30 \mathrm{~min}$ administration prolonged the TFL $(\% \mathrm{MPE}=44.00 \pm 16.95$; $\mathrm{P}<0.05$; Fig. 2), demonstrating that ERKs serve an important role in morphine tolerance. 


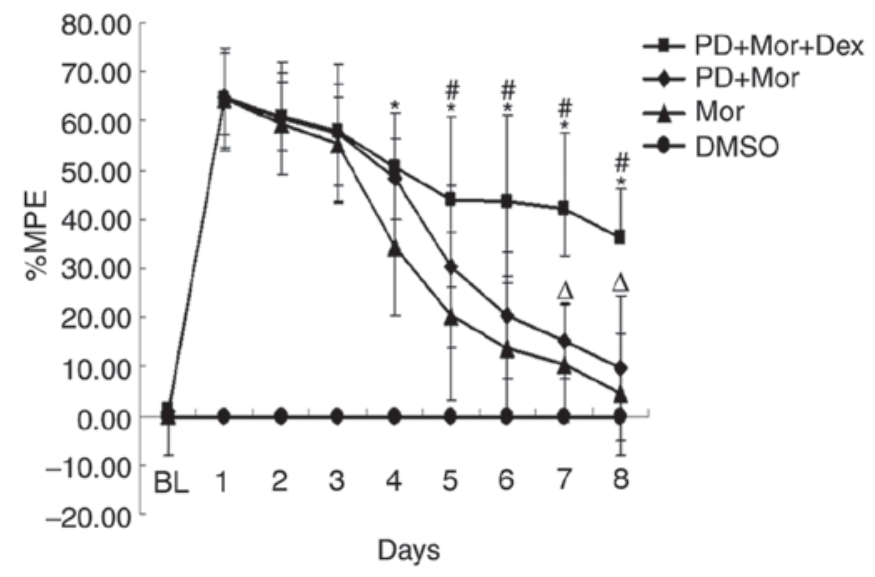

Figure 2. Effects of pretreatment with PD98059 in the tail-flick test. ${ }^{*} \mathrm{P}<0.05$, $\mathrm{PD}+$ Mor+Dex vs. Mor; ${ }^{\text {}} \mathrm{P}<0.05$, PD+Mor+Dex vs. PD+Mor, ${ }^{\Delta} \mathrm{P}>0.05$, $\mathrm{PD}+$ Mor vs. Mor. $\mathrm{n}=5$ for each group. DMSO, treatment with dimethyl sulfoxide, RU38486 and Dex treatment for 7 days (10 $\mu 1$ twice daily); Mor, treatment with morphine for 7 days (10 $\mu \mathrm{g}$ twice daily); PD+Mor+Dex, cotreatment of PD98059 $(10 \mu \mathrm{g})$, morphine $(10 \mu \mathrm{g})$ and Dex $(2 \mu \mathrm{g})$ for 7 days twice daily; PD+Mor, cotreatment of morphine $(10 \mu \mathrm{g})$ and PD98059 $(10 \mu \mathrm{g})$ for 7 days twice daily; MPE, maximal possible effect; RU38486, mifepristone; Dex, dexamethasone.

Colocalization of GR and p-ERK1/2. Double staining immunofluorescence was conducted to determine the colocalization of GR and p-ERK1/2 in the morphine-tolerant rats (Fig. 3; white arrow positioning area). The distribution of GR immunoreactivity (IR) was primarily within the spinal cord superficial laminae (I-II) compared with the deeper laminae (III-IV) (Fig. 3A-D). Following repeated morphine administration or combined with Dex, the content of GR increased in the spinal cord dorsal horn (Fig. 3B and D). In addition, p-ERK1/2 was primarily located in the superficial layer of the spinal cord (I-II). Subsequent to GR antagonist RU38486 application, the expression of p-ERK1/2 was increased (Fig. 3G); whereas, the expression of $\mathrm{p}$-ERK1/2 decreased following the application of Dex (Fig. 3H). The combination of GR and p-ERK1/2 immunostaining demonstrated that approximately all the GR-IR sites in the I-II layer expressed p-ERK1/2, indicating that GR may regulate the role of morphine through ERK (Fig. 3I-K).

Expression of spinal cord GR and p-ERK. The results of the western blot analysis demonstrated that compared with the saline control, there was an upregulation of GR and p-ERK1/2 within the spinal cord following chronic treatment with morphine on day 7 (Fig. 4A; $\mathrm{P}<0.05 ; \mathrm{n}=4-5$ ), which is consistent with previous studies that demonstrated a time-dependent increase in spinal GR expression following chronic treatment with morphine (10 $\mu \mathrm{g}$ twice daily for 6 days) (6,7). Treatment with Dex induced an upregulation of spinal GR expression compared with the morphine group and the saline control (Fig. 4B; $\mathrm{P}<0.05 ; \mathrm{n}=4-5$ ), indicating that coadministration of RU38486 decreased the expression of spinal GR induced by morphine. In this experiment, compared with the morphine group, the expression level of spinal p-ERK1/2 increased following coadministration of morphine with RU38486 for 6 days (Figs. 4 and 5; $\mathrm{P}<0.05$; $\mathrm{n}=4-5)$.

\section{Discussion}

The mechanisms underlying opioid analgesic tolerance are complex and involve adaptations in opioid receptor activity at the cellular and molecular levels, and at the level of spinal or superspinal neuronal network signal nociception (27-29). The spinal cord dorsal horn is the first transit point of the nociceptive pathway; from $\mathrm{A} \delta$ and $\mathrm{C}$ fibers, afferent nociceptive information ascending through the dorsal horn projection neurons is passed to the upper senior center. The spinal cord receives nociceptive information and processes and integrates this noxious information (30). It is an important pain modulation center. DeLander et al (31) indicated that the spinal cord is a key site of opioid tolerance, and drugs that inhibit $\mu$ opioid receptor expression can significantly antagonize opioid tolerance.

There are numerous methods of inducing chronic morphine tolerance; the present study used the method of IT catheters to deliver drugs directly to the spinal cord lumbar enlargement. In the assessment of opioid tolerance, the majority of behavioral studies examine the TFL, a pain response indicator that is a simple spinal reflex without the involvement of the superspinal cord nervous system; it coordinates information on noxious stimulation of the spinal cord itself (32). In the first experiment, following 6 days of consecutive injection, morphine resulted in a significant decrease in TFL compared with the control group rats. Coadministration of morphine and the GR antagonist RU38486 prevented the successive declining of TFL between days 5 and 7, and the effect of Dex was the opposite.

Double immunofluorescence staining was conducted to determine the colocalization of GRs and p-ERKs. Studies have demonstrated that GRs are located within the spinal cord dorsal horn, and activation of neuronal GRs contributes to neural plasticity associated with neuronal injury $(17,33,34)$. Furthermore, activation of GRs has been demonstrated to modulate morphine-induced antinociception and morphine tolerance $(6,35)$. ERK as a member of the MAPK family is downstream of numerous kinases and is activated in primary sensory neurons, dorsal horn neurons and spinal glial cells when exposed to a number of factors, including nociceptive stimuli, growth factors and inflammatory mediators. The activation of ERK consequently contributes to the induction and maintenance of sensitization via transcriptional, translational and posttranslational regulation (15). Data from in vitro and in vivo experiments suggest that the phosphorylation of MAPK serves a role in the chronic morphine-induced increase in calcitonin gene-associated peptide and substance $\mathrm{P}$ levels in dorsal root ganglion neurons, indicating MAPK involvement in morphine-induced antinociception (35). As a part of a critical signaling pathway, the association between GR and ERK was first tested. It was revealed that certain neurons contained IR sites for GR and p-ERK in morphine-tolerant animals and other groups, indicating an association between GR and ERK in response to chronic morphine exposure.

The expression of spinal GR and p-ERK1/2 was assessed by western blotting; compared with the saline control, upregulation of GR and p-ERK1/2 was observed within the spinal cord following chronic treatment with morphine on day 7 , similar to a previous study, which demonstrated that an increase in p-ERK1/2 level in the spinal cord was detected following IT injection of morphine (15 $\mu \mathrm{g} /$ day) for 7 days in rats (36). Rats 

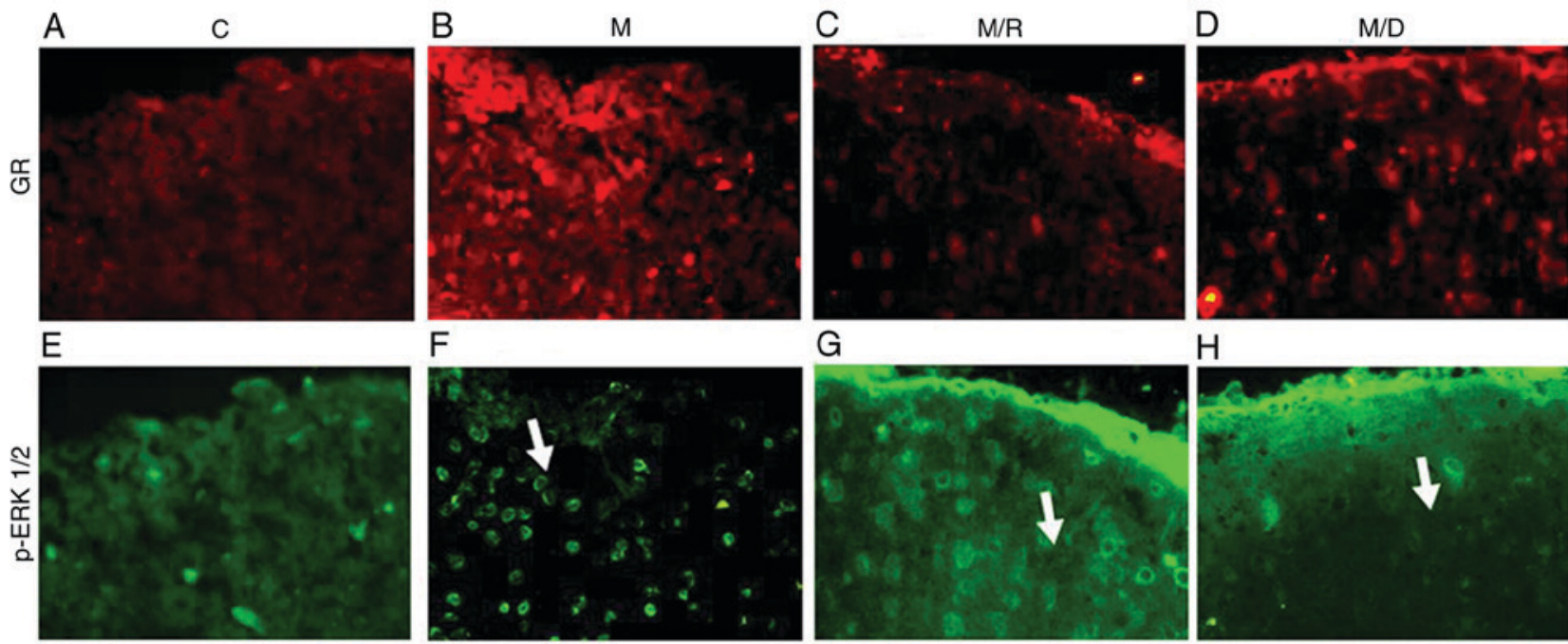

$\mathrm{F}$

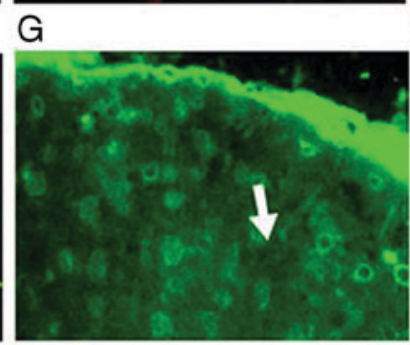

$\mathrm{H}$
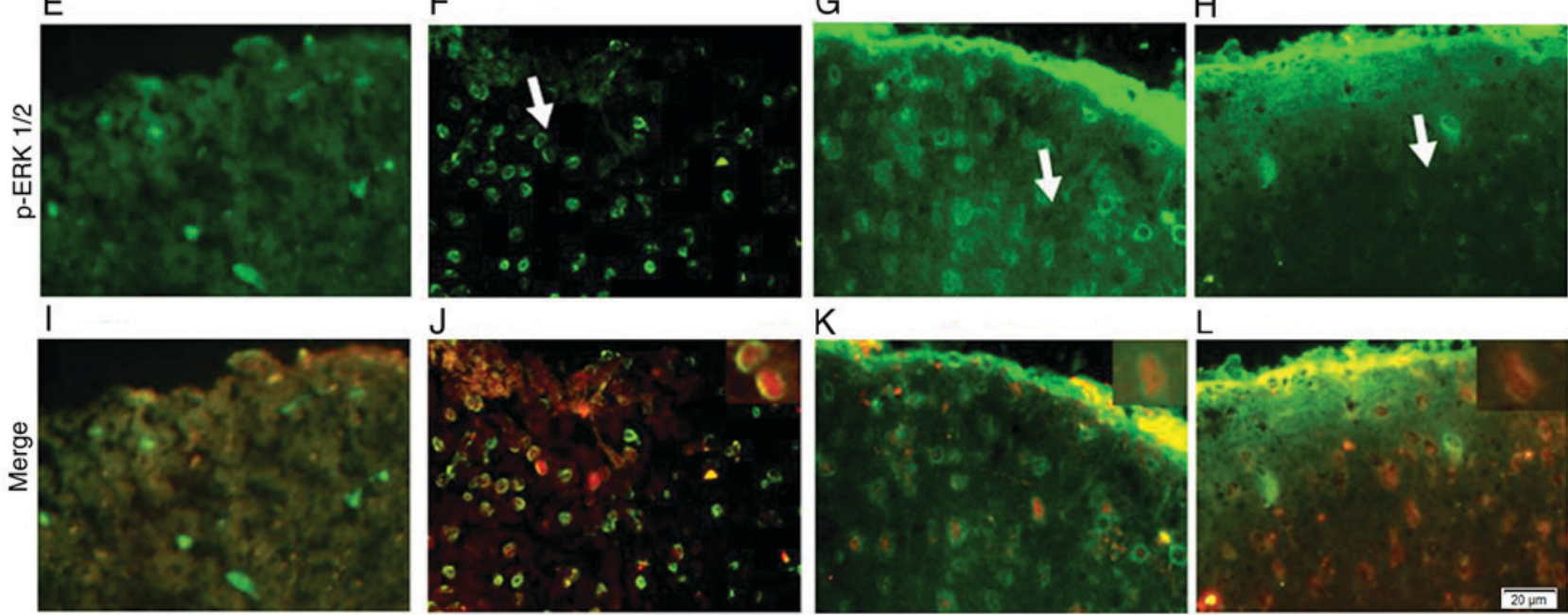

Figure 3. Colocalization of GR and p-ERK1/2 (indicated by the white arrows). Double immunostaining of GR in (A) C group, (B) M group, (C) M/R group and (D) M/D group, and of p-ERK in (E) C group, (F) M group, (G) M/R group and (H) M/D group, revealed the colocalization in the dorsal horn of the lumbar spinal cord as indicated in yellow. The images of (I) C group, (J) M group, (K) M/R group and (L) M/D group are merged (the magnification of smaller images in $\mathrm{K}$ and $\mathrm{L}$ is $\mathrm{x} 1,000)$. Scale bar (in F): A-L, $20 \mu \mathrm{m}$. $\mathrm{n}=5$ for each group. C, Saline treatment for 6 days (10 $\mu 1$, twice daily); M, treatment with morphine for 6 days (10 $\mu \mathrm{g}$ twice daily); M/R, cotreatment of morphine $(10 \mu \mathrm{g})$ and RU38486 $(2 \mu \mathrm{g})$ for 6 days twice daily; M/D, cotreatment of morphine (10 $\mu \mathrm{g})$ and RU38486 (4 $\mu \mathrm{g})$ for 6 days twice daily; GR, glucocorticoid receptor; p-ERK, phosphorylated extracellular signal-regulated kinase; RU38486, mifepristone.

A

C M $M / R$ M/D

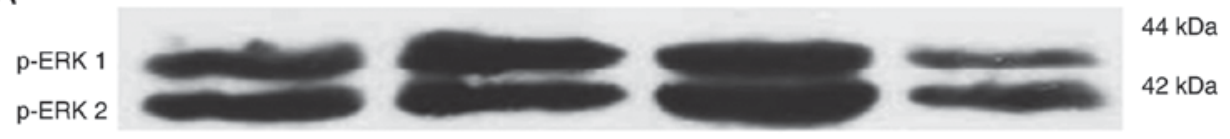

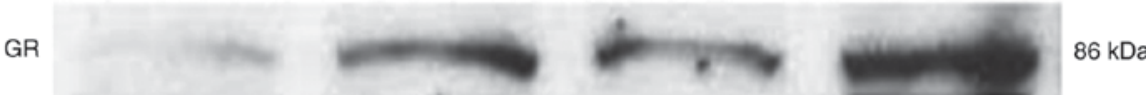
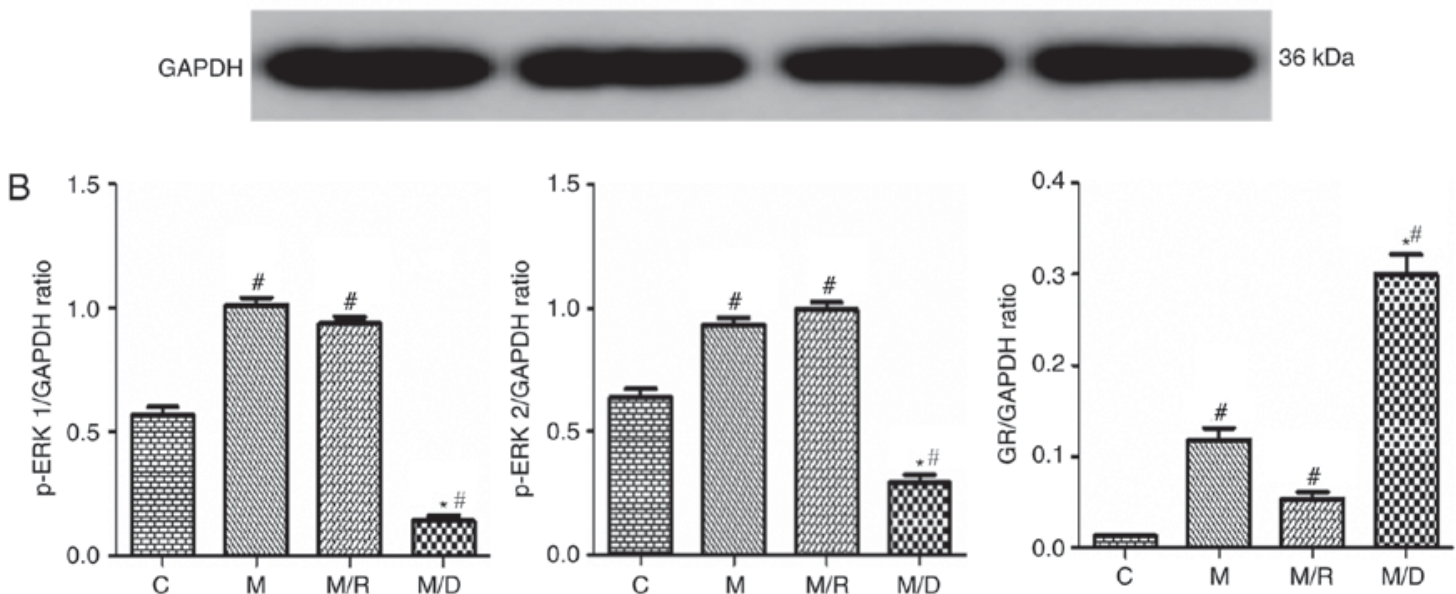

Figure 4. (A and B) Expression of spinal cord GR and p-ERK. ${ }^{\#} \mathrm{P}<0.05$ vs. C; ${ }^{*} \mathrm{P}<0.05$ vs. M. C, saline control; M, morphine; M/R, morphine+RU38486; M/D, morphine+dexamethasone; p-ERK 1/2, phosphorylated extracellular signal-regulated kinase 1/2; GR, glucocorticoid receptor; RU38486, mifepristone.

treated with morphine and RU38486 demonstrated that the expression of spinal GR decreased compared with treatment with morphine, suggesting that RU38486 may prevent the development of morphine tolerance, and the behavior test was 

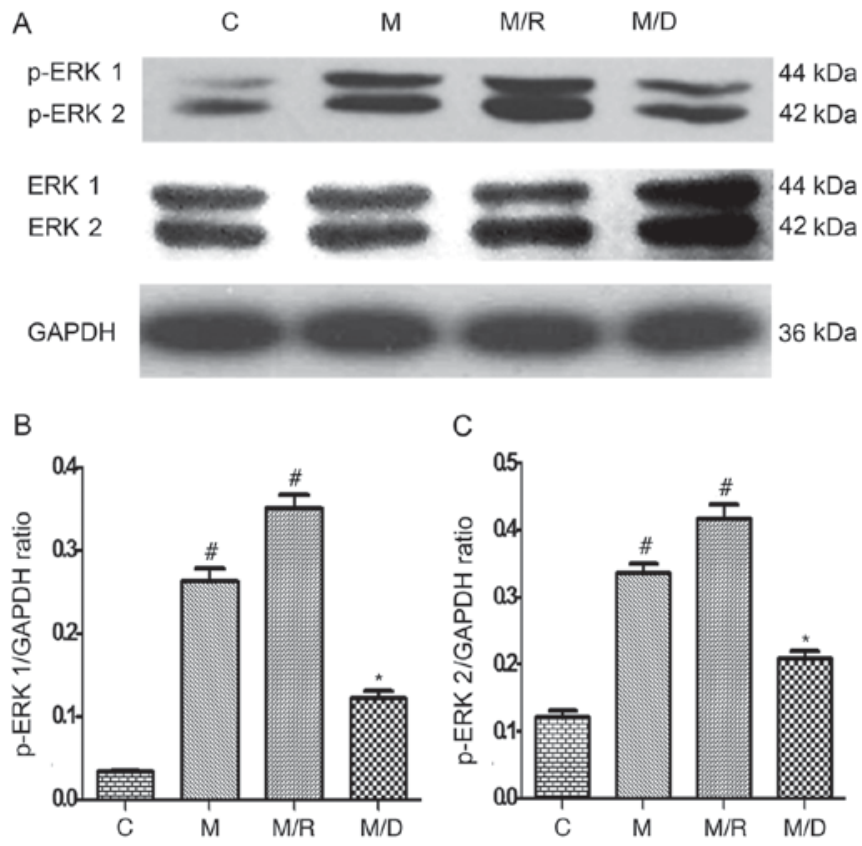

Figure 5. (A and B) Expression of spinal cord p-ERK. ${ }^{\#} \mathrm{P}<0.05$ vs. C; ${ }^{*} \mathrm{P}<0.05$ vs. M. C, saline control. M, morphine; M/R, morphine+RU38486; $\mathrm{M} / \mathrm{D}$, morphine+dexamethasone; p-ERK 1/2, phosphorylated extracellular signal-regulated kinase 1/2; GR, glucocorticoid receptor; RU38486, mifepristone.

in accordance with this. However, the expression of spinal p-ERK1/2 was decreased subsequent to treatment with Dex and morphine on day 7 compared with the morphine group. The tail flick test demonstrated that the treatment with Dex and morphine for 6 days was unable prevent the development of morphine tolerance. In the second experiment, IT administration of the MEK inhibitor PD98059 $(10 \mu \mathrm{g} / 10 \mu \mathrm{l})$ prior to IT injection of morphine and Dex delayed the development of tolerance in the rats. The possible mechanism is that Dex functions independently, as demonstrated by Croxtall et al (37). This previous study demonstrated that Dex reduces the level of p-ERK1/2 in a GR-dependent manner; however, a transcription-independent mechanism was observed in A549 cells. A study examining ERK-deficient mice may be helpful to further elucidate the role of ERK in tolerance and dependence (38). It is additionally important to note that the MEK inhibitor PD98059 requires sufficient pretreatment time ( $>20 \mathrm{~min})$ to obtain optimal membrane permeability (36).

The addition of a second drug to a morphine infusion has been demonstrated to be an effective strategy for attenuating morphine tolerance and maintaining the antinociceptive efficacy of morphine in chronic morphine-infused rats (39-41). The present results suggested that a GR inhibitor, including RU38486 may be useful in preventing the development of opioid tolerance, an issue of substantial clinical relevance. There is a clear association between spinal GR and the expression of p-ERK1/2, contributory to the development of morphine tolerance. The present study is different from the previous study published by the present research group (42). The double-staining immunofluorescence technique detected the expression of GR and p-ERK1/2, and demonstrated the association between the two. In combination with the results of the western blot analyses, it was quantitatively demonstrated that ERK is involved in the development of chronic morphine tolerance. Secondly, the introduction of a MAPK inhibitor in the present study further confirmed that GR may increase the duration of morphine tolerance by signaling via the MAPK/ERK pathway, which suggests a more logical conclusion: GR may be involved in chronic morphine tolerance through ERK1/2. However, it must be emphasized that these findings do not exclude other interactions between the spinal GR and morphine tolerance. For example, the spinal cord N-methyl-D-aspartate (NMDA) receptor and protein kinase $\mathrm{C} \gamma$, which are regulated through GRs, influence the development of morphine tolerance, and the NMDA receptor and the MAPK pathway are involved in synaptic plasticity (43-46).

In conclusion, the present study demonstrates that cotreatment of a GR inhibitor with morphine may attenuate the development of morphine tolerance, and there may be an association between spinal GRs and the MAPK signaling pathway.

\section{Acknowledgements}

The authors thank Mr. Xie KL for his editorial support.

\section{Funding}

No funding was received.

\section{Availability of data and materials}

All data generated or analyzed during this study are included in this published article.

\section{Authors' contributions}

MLZ and YC made contributions to experimental design, data collection and manuscript writing. CL and JBW contributed to data collection, data analysis and interpretation. YHY is responsible for the overall design of the experiment, the revision of the contents and the publication of the paper.

\section{Ethics approval and consent to participate}

All animal procedures in the present study were approved by the Animal Care and Use Committee of Tianjin Medical University and in accordance with the National Institutes of Health Guide for the Care and Use of Laboratory Animals.

\section{Consent for publication}

Not applicable.

\section{Competing interests}

The authors declare that they have no competing interests.

\section{References}

1. Bailey CP, Llorente J, Gabra BH, Smith FL, Dewey WL, Kelly E and Henderson G: Role of protein kinase $\mathrm{C}$ and mu-opioid receptor $(\mathrm{MOPr})$ desensitization in tolerance to morphine in rat locus coeruleus neurons. Eur J Neurosci 29: 307-318, 2009. 
2. Chu J, Zheng H, Loh HH and Law PY: Morphine-induced mu-opioid receptor rapid desensitization is independent of receptor phosphorylation and beta-arrestins. Cell Signal 20 1616-1624, 2008

3. Sim-Selley LJ, Scoggins KL, Cassidy MP, Smith LA, Dewey WL, Smith FL and Selley DE: Region-dependent attenuation of mu opioid receptor-mediated G-protein activation in mouse CNS as a function of morphine tolerance. Br J Pharmacol 151: 1324-1333, 2007.

4. Bull FA, Baptista-Hon DT, Sneddon C, Wright L, Walwyn W and Hales TG: Src kinase inhibition attenuates morphine tolerance without affecting reinforcement or psychomotor stimulation. Anesthesiology 127: 878-889, 2017.

5. Wilson-Poe AR, Jeong HJ and Vaughan CW: Chronic morphine reduces the readily releasable pool of GABA, a presynaptic mechanism of opioid tolerance. J Physiol 595: 6541-6555, 2017.

6. Lim G, Wang S, Zeng Q, Sung B and Mao J: Spinal glucocorticoid receptors contribute to the development of morphine tolerance in rats. Anesthesiology 102: 832-837, 2005.

7. Lim G, Wang S, Zeng Q, Sung B and Mao J: Evidence for a long-term influence on morphine tolerance after previous morphine exposure: Role of neuronal glucocorticoid receptors. Pain 114: 81-92, 2005

8. Narita M, Ioka M, Suzuki M, Narita M and Suzuki T: Effect of repeated administration of morphine on the activity of extracellular signal regulated kinase in the mouse brain. Neurosci Lett 324: 97-100, 2002.

9. Robbins TW and Everitt BJ: Drug addiction: Bad habits add up. Nature 398: 567-570, 1999.

10. Williams JT, Christie MJ and Manzoni O: Cellular and synaptic adaptations mediating opioid dependence. Physiol Rev 81: 299-343, 2001

11. Deng XT, Han Y, Liu WT and Song XJ: B vitamins potentiate acute morphine antinociception and attenuate the development of tolerance to chronic morphine in mice. Pain Med 18: 1961-1974, 2017.

12. Pan Y, Sun X, Jiang L, Hu L, Kong H, Han Y, Qian C, Song C, Qian Y and Liu W: Metformin reduces morphine tolerance by inhibiting microglial-mediated neuroinflammation. J Neuroinflammation 13: 294, 2016

13. Bao Y, Gao Y, Yang L, Kong X, Yu J, Hou W and Hua B: The mechanism of mu-opioid receptor (MOR)-TRPV1 crosstalk in TRPV1 activation involves morphine anti-nociception, tolerance and dependence. Channels (Austin) 9: 235-243, 2015.

14. Jiang C, Xu L, Chen L, Han Y, Tang J, Yang Y, Zhang G and Liu W: Selective suppression of microglial activation by paeoniflorin attenuates morphine tolerance. Eur J Pain 19: 908-919, 2015

15. Gutstein HB, Rubie EA, Mansour A, Akil H and Woodgett JR Opioid effects on mitogen-activated protein kinase signaling cascades. Anesthesiology 87: 1118-1126, 1997.

16. Fukuda K, Kato S, Morikawa H, Shoda T and Mori K: Functiona coupling of the delta-, mu-, and kappa-opioid receptors to mitogenactivated protein kinase and arachidonate release in Chinese hamster ovary cells. J Neurochem 67: 1309-1316, 1996.

17. Cameron SA and Dutia MB: Lesion-induced plasticity in rat vestibular nucleus neurones dependent on glucocorticoid receptor activation. J Physiol 518: 151-158, 1999.

18. Garabedian MJ, Harris CA and Jeanneteau F: Glucocorticoid receptor action in metabolic and neuronal function. F1000Res 6 : $1208,2017$.

19. Takahashi M, Sugimachi K and Kaneto H: Role of adrenal glucocorticoids in the blockade of the development of analgesic tolerance to morphine by footshock stress exposure in mice. Jpn J Pharmacol 51: 329-336, 1989.

20. Clark AR and Lasa M: Crosstalk between glucocorticoids and mitogen-activated protein kinase signalling pathways. Curr Opin Pharmacol 3: 404-411, 2003

21. Wang S, Lim G, Zeng Q, Sung B, Ai Y, Guo G, Yang L and Mao J: Expression of central glucocorticoid receptors after peripheral nerve injury contributes to neuropathic pain behaviors in rats. J Neurosci 24: 8595-8605, 2004.

22. Ma W and Quirion R: The ERK/MAPK pathway, as a target for the treatment of neuropathic pain. Expert Opin Ther Targets 9 699-713, 2005.

23. Mayer DJ, Mao J, Holt J and Price DD: Cellular mechanisms of neuropathic pain, morphine tolerance, and their interactions Proc Natl Acad Sci USA 96: 7731-7736, 1999.

24. LoPachin RM, Rudy TA and Yaksh TL: An improved method for chronic catheterization of the rat spinal subarachnoid space. Physiol Behav 27: 559-561, 1981.

25. Mao J: Opioid-induced abnormal pain sensitivity: Implications in clinical opioid therapy. Pain 100: 213-217, 2002.
26. Cui Y, Chen Y, Zhi JL, Guo RX, Feng JQ and Chen PX: Activation of p38 mitogen-activated protein kinase in spinal microglia mediates morphine antinociceptive tolerance. Brain Res 1069: 235-243, 2006

27. Mao J, Price DD and Mayer DJ: Experimental mononeuropathy reduces the antinociceptive effects of morphine: Implications for common intracellular mechanisms involved in morphine tolerance and neuropathic pain. Pain 61: 353-364, 1995.

28. Gardell LR, Wang R, Burgess SE, Ossipov MH, Vanderah TW, Malan TP Jr, Lai J and Porreca F: Sustained morphine exposure induces a spinal dynorphin-dependent enhancement of excitatory transmitter release from primary afferent fibers. J Neurosci 22 : 6747-6755, 2002

29. Trang T, Quirion R and Jhamandas K: The spinal basis of opioid tolerance and physical dependence: Involvement of calcitonin gene-related peptide, substance $\mathrm{P}$, and arachidonic acid-derived metabolites. Peptides 26: 1346-1355, 2005.

30. Guo D and Hu J: Spinal presynaptic inhibition in pain control. Neuroscience 283: 95-106, 2014

31. DeLander GE, Portoghese PS and Takemori AE: Role of spinal mu opioid receptors in the development of morphine tolerance and dependence. J Pharmacol Exp Ther 231: 91-96, 1984.

32. Pitcher GM, Yashpal K, Coderre TJ and Henry JL: Mechanisms underlying antinociception provoked by heterosegmental noxious stimulation in the rat tail-flick test. Neuroscience 65: 273-281, 1995

33. Cintra A, Molander C and Fuxe K: Colocalization of Fos- and glucocorticoid receptor-immunoreactivities is present only in a very restricted population of dorsal horn neurons of the rat spinal cord after nociceptive stimulation. Brain Res 632: 334-338, 1993.

34. De Nicola AF, Moses DF, Gonzalez S and Orti E: Adrenocorticoid action in the spinal cord: Some unique molecular properties of glucocorticoid receptors. Cell Mol Neurobiol 9: 179-192, 1989

35. Capasso A, Di Giannuario A, Loizzo A, Pieretti S and Sorrentino L: Central interaction of dexamethasone and RU-38486 on morphine antinociception in mice. Life Sci 51: PL139-PL143, 1992.

36. Wang Z, Ma W, Chabot JG and Quirion R: Cell-type specific activation of p38 and ERK mediates calcitonin gene-related peptide involvement in tolerance to morphine-induced analgesia. FASEB J 23: 2576-2586, 2009

37. Croxtall JD, Choudhury Q and Flower RJ: Glucocorticoids act within minutes to inhibit recruitment of signalling factors to activated EGF receptors through a receptor-dependent, transcription-independent mechanism. Br J Pharmacol 130: 289-298, 2000

38. Mazzucchelli C, Vantaggiato C, Ciamei A, Fasano S, Pakhotin P, Krezel W, Welzl H, Wolfer DP, Pages G, Valverde O, et al: Knockout of ERK1 MAP kinase enhances synaptic plasticity in the striatum and facilitates striatal-mediated learning and memory. Neuron 34: 807-820, 2002.

39. Tai YH, Wang YH, Wang JJ, Tao PL, Tung CS and Wong CS Amitriptyline suppresses neuroinflammation and up-regulates glutamate transporters in morphine-tolerant rats. Pain 124 77-86, 2006

40. Wen ZH, Wu GJ, Chang YC, Wang JJ and Wong CS Dexamethasone modulates the development of morphine tolerance and expression of glutamate transporters in rats. Neuroscience 133: 807-817, 2005.

41. Wong CS, Hsu MM, Chou R, Chou YY and Tung CS: Intrathecal cyclooxygenase inhibitor administration attenuates morphine antinociceptive tolerance in rats. Br J Anaesth 85: 747-751, 2000

42. Chen Y, Yu YH, Zhai ML, Wang Z and Wang GL: Participation of glucocorticoid receptors in morphine tolerance development through the signal pathway of extracellular signal-regulated kinase.Zhonghua Yi Xue Za Zhi 91: 1272-1275, 2011 (In Chinese).

43. Martel MA, Wyllie DJ and Hardingham GE: In developing hippocampal neurons, NR2B-containing N-methyl-D-aspartate receptors (NMDARs) can mediate signaling to neuronal survival and synaptic potentiation, as well as neuronal death. Neuroscience 158: 334-343, 2009.

44. Urakubo H, Honda M, Froemke RC and Kuroda S: Requirement of an allosteric kinetics of NMDA receptors for spike timing-dependent plasticity. J Neurosci 28: 3310-3323, 2008.

45. Ota KT, Pierre VJ, Ploski JE, Queen K and Schafe GE: The NO-cGMP-PKG signaling pathway regulates synaptic plasticity and fear memory consolidation in the lateral amygdala via activation of ERK/MAP kinase. Learn Mem 15: 792-805, 2008.

46. ToyodaH,ZhaoMG,XuH,WuLJ,RenMandZhuoM:Requirement of extracellular signal-regulated kinase/mitogen-activated protein kinase for long-term potentiation in adult mouse anterior cingulate cortex. Mol Pain 3: 36, 2007. 